\title{
Anti-oxidative response in susceptible and resistant cultivars of Oryza sativa $L$. in response to infection by Rhizoctonia solani
}

\author{
Sorabh Chaudhary*¹, Mukesh Kumar ${ }^{1}$, R.S. Sengar ${ }^{1}$, Pooran Chand ${ }^{2}$, Prashant Mishra ${ }^{3}$ and \\ Akash Tomar ${ }^{4}$
}

${ }^{1}$ Deparment of Agriculture Biotechnology, ${ }^{2}$ Deparment of Genetics \& Plant Breeding, ${ }^{3}$ Department of Plant pathology, ${ }^{4}$ Deparment of Recombination Techniques, S. V. P. University of Agriculture \& Technology, Meerut-250110 (Uttar Pradesh), India

*Email: sorabh.gene@gmail.com

\begin{abstract}
Changes in the activities of peroxidase, ascorbate peroxidase, catalase and superoxide dismutase in susceptible (Pusa 1121) and resistant (Tetep) rice cultivars in response to infection by Rhizoctonia solani were studied. A positive association was found between peroxidase activity with the degree of infection in both rice cultivars inoculated with $R$. solani. A significant increase in peroxidase activity was observed in $R$. solaniinoculated rice leaf sheaths $1^{\text {st }}$ day after inoculation and the maximum enzyme activity was recorded 3 days after inoculation at which period a 3-fold increase in peroxidase activity was observed compared to the untreated control. Ascorbate peroxidase and catalase activities significantly increased 1-2 days after inoculation and the maximum enzyme activities were recorded 5 days after inoculation in resistant cultivar. Superoxide dismutase activity increased significantly at 2 days after inoculation and increased progressively, reaching four times the control value at 7 days after inoculation. However, higher superoxide dismutase activity was recorded in resistant cultivar.
\end{abstract}

Key words: Oryza sativa, R. solani, antioxidant enzyme, catalase, ascorbate, ascorbate peroxidase, superoxide dismutase

Paper cited: Chaudhary, S., Kumar, M., Sengar, R.S., Chand, P., Mishra, P. and Tomar, A. (2017). Anti-oxidative response in susceptible and resistant cultivars of Oryza sativa L. in response to infection by Rhizoctonia solani. South Asian Journal of Food Technology and Environment, 3(1): 507-515.

\section{Introduction}

Plants respond to infection by pathogens by activating a number of defense responses. These inducible defense responses include hypersensitive cell death, production of phytoalexins, accumulation of pathogenesisrelated (PR) proteins, and induction of oxidative burst, lignification and cross-linking of wall glycoprotein. However, the timing and magnitude of induction of these defense mechanisms differ between resistant and susceptible cultivars (Dixon and Harrison, 1990). Reactive oxygen species (ROS) are formed in biological systems as part of normal metabolism. Adverse environmental factors result in increased levels of ROS that are detrimental to the plant. To avoid damage caused by these excess ROS, plants have developed elaborate mechanisms to manage them at sustainable levels.

Upon pathogen invasion, an oxidative burst is one of the most rapid defence reactions elicited in the plant, which in turn leads to the transient production of high levels of reactive oxygen species (ROS) that include superoxide $\left(\mathrm{O}_{2}{ }^{-}\right)$, hydrogen peroxide $\left(\mathrm{H}_{2} \mathrm{O}_{2}\right)$ and the hydroxyl radical $(\cdot \mathrm{OH})$. Reactive oxygen species produced in the oxidative burst has been demonstrated not only to protect against invading pathogens but also to function as signaling molecules which activate plant defence responses in many plant-pathogen interactions (Lamb and Dixon, 1997; Dangl and Jones, 2001; Apel and Hirt, 2004; Aguirre et al., 2005). Reactive oxygen species burst in the host has a direct toxic effect on the 
pathogen (Delledonne et al., 2001). Plants have evolved to efficiently scavenge these damaging effects by triggering a system involving both enzymatic and non-enzymatic antioxidants, where the enzymatic protective mechanism operates by sequentially and simultaneously inducing a number of antioxidant enzymes (Panda, 2007). Enzymes play an important role in lowering the ROS levels and helping avoid oxidative stress. Superoxide dismutase, catalase, ascorbate peroxidase, and glutathione reductase play a vital role in combating oxidative stress. Measuring these enzyme activities spectrophotometrically provides researchers an easy and precise way to study and understand an important part of the defense against oxidative stress. In the present study, the effect of $R$. solani infection on the activities of enzymatic scavengers of active oxygen species viz., peroxidase, catalase, superoxide dismutase and ascorbate peroxidase in susceptible and resistant cultivars of rice was studied.

\section{Materials and Methods}

\section{Plant materials, pathogen and inoculation}

The fungus, Rhizoctonia solani was isolated from sheath blight infected rice plants and maintained on potato dextrose agar (PDA) medium under in-vitro conditions.

The susceptible and resistant rice cultivars viz., Pusa 1121 and Tetep obtained from the Department of Genetics and Plant Breeding, SVP University of Ag. \& Tech., Meerut were raised in earthen pots $(25 \mathrm{~cm}$ in diameter) containing autoclaved rice field soil. Actively tillering plants of 45 days old were inoculated with Rhizoctoniai solani by inserting sclerotia obtained from the culture grown on PDA for 10-12 days, between sheath and culm just above the water level. At various days after inoculation, plant samples were collected, frozen in liquid nitrogen and various analysis were made. Samples from each treatment were analysed thrice, and the experiment was performed twice. The treatment values from two independent experiments were averaged and plotted by time.

\section{Assay of peroxidase activity}

The enzyme extract was prepared by homogenizing $1.0 \mathrm{~g}$ of rice leaf sheaths in $2 \mathrm{ml}$ of $0.1 \mathrm{M}$ sodium phosphate buffer $(\mathrm{pH} 6.5)$ at $4^{\circ} \mathrm{C}$. The homogenate was centrifuged at $15,000 \mathrm{~g}$ at $4^{\circ} \mathrm{C}$ for $30 \mathrm{~min}$. The supernatant was used as enzyme source.

Peroxidase activity was determined according to the procedure given by Srivastava (1987). In enzyme assay, pyrogallol oxidation was maintained in the mixture containing 50 $\mathrm{mM}$ phospate buffer ( $\mathrm{pH}$ 6.5). In a sample cuvette, $1.5 \mathrm{ml}$ of $0.05 \mathrm{M}$ pyrogallol and 100 $\mu \mathrm{l}$ of enzyme extract were taken up. In reference cuvette, inactivated enzyme (by boiling) extract $(100 \mu \mathrm{l})$ was taken along with $1.5 \mathrm{ml}$ of $0.05 \mathrm{M}$ pyrogallol. The reading was adjusted to zero at $420 \mathrm{~nm}$ in a Hitachi 200-20 Spectrophotometer. To initiate the reaction, $100 \mu 1$ of hydrogen peroxide ( $1 \%)(\mathrm{v} / \mathrm{v})$ was added to the sample cuvette and the absorbance values were read at $420 \mathrm{~nm}$. The enzyme activity was expressed as $\mu \mathrm{kat}^{-\mathrm{g}^{-1}}$ tissue.

\section{Assay of ascorbate peroxidase activity}

The enzyme extract was prepared by homogenizing $1 \mathrm{~g}$ of rice leaf sheaths in $2 \mathrm{ml}$ of $0.1 \mathrm{M}$ sodium phosphate buffer $(\mathrm{pH} 7.0)$ at $4^{\circ} \mathrm{C}$. The homogenate was centrifuged at $15,000 \mathrm{~g}$ at $4^{\circ} \mathrm{C}$ for $30 \mathrm{~min}$. The supernatant was used as enzyme source. The assay for ascorbate peroxidase was performed in a $3 \mathrm{ml}$ quartz cuvette containing $0.5 \mathrm{mM}$ ascorbate, $0.1 \mathrm{M}$ phosphate buffer ( $\mathrm{pH} 7.0$ ), $2 \mathrm{mM} \mathrm{H}_{2} \mathrm{O}_{2}$ and $0.01 \mathrm{ml}$ of enzyme extract. The decrease in absorbance of ascorbate at $265 \mathrm{~nm}$ due to ascorbate oxidation was measured (Asada, 1984). The enzyme activity was expressed as $\mu$ kat.g ${ }^{-1}$ tissue.

\section{Assay of catalase activity}

The enzyme extract for measuring catalase activity in rice leaf sheath was prepared as described for colorimetric 
determination of SOD activity. The standard reaction mixture contained $50 \mathrm{mM}$ phosphate buffer (pH 7.0) and $15 \mathrm{mM} \mathrm{H}_{2} \mathrm{O}_{2}$. A $100 \mu 1$ sample of the enzyme extract was added to 2.9 $\mathrm{ml}$ of the standard reaction mixture to initiate the reaction. Tube contents were shaken and the decrease in $\mathrm{H}_{2} \mathrm{O}_{2}$ concentration was measured as the decline in $\mathrm{A}_{240}$ during the first 10 min using a Beckman DU64 spectrophotometer (Chance and Maehly, 1955). The enzyme activity was expressed as $\mu$ kat.g ${ }^{-1}$ tissue.

\section{Assay of superoxide dismutase activity}

The enzyme extract was prepared by homogenizing $1 \mathrm{~g}$ of rice leaf sheaths in $2 \mathrm{ml}$ of $0.2 \mathrm{M}$ citrate phosphate buffer $(\mathrm{pH} 6.5)$ at $4^{\circ} \mathrm{C}$. The homogenate was centrifuged at $15,000 \mathrm{~g}$ at $4^{\circ} \mathrm{C}$ for $30 \mathrm{~min}$. The supernatant served as enzyme source. SOD activity was determined as its ability to inhibit the photochemical reduction of nitroblue tetrazolium (NBT) (Giannospolitis and Ries, 1977). The assay mixture $(3 \mathrm{ml})$ contained 50 $\mathrm{mM}$ sodium phosphate buffer ( $\mathrm{pH} 7.8$ ), 13 $\mathrm{mM}$ methionine, $75 \mu \mathrm{M}$ nitroblue tetrazolium (NBT), $2 \mu \mathrm{M}$ riboflavin, $0.1 \mathrm{mM}$ EDTA and $100 \mu 1$ of the enzyme extract. The riboflavin was added last. Tubes were shaken and placed under a $40-\mathrm{W}$ fluorescent lamp at $25^{\circ} \mathrm{C}$. The reaction was initiated and terminated by turning the light on and off. The $\mathrm{A}_{560}$ was measured against identical non-illuminated samples. Additional tubes containing only the assay mixture without the enzyme extract were illuminated in parallel to the sample tubes to determine $\mathrm{A}_{560}$. Each extract was subtracted from the maximum $\mathrm{A}_{560}$; the mathematical difference was then divided by the maximum $\mathrm{A}_{560}$ and multiplied by 100 to obtain the percentage inhibition of NBT photo-reduction. The SOD activity was expressed in SOD units. $\mathrm{g}^{-1}$ tissue $(50$ percent NBT inhibition $=1$ unit) (Belid EI-Moshaty et al., 1993).

\section{Results and Discussion}

Change in the activities of peroxidase, ascorbate peroxidase, superoxidase dismutase and catalase in susceptible (cv. Pusa 1121) and resistant ( $c v$. Tetep) cultivars of rice in response to infection by Rhizoctonia solani were studied.

Peroxidase activity increased in both the resistant and susceptible cultivars with infection of Rhizoctonia solani. A positive association was found between peroxidase activity with the degree of infection in both rice $c v s$ viz., Pusa 1121 (susceptible) and Tetep (resistant). Peroxidase activity increased concomitantly with the increase of infection in both the cultivars. PO activity significantly increased in rice leaf sheath from 1 day after inoculation with $R$. solani and the maximum increased was observed 3 days after inoculation at which period a 3 -fold increase in PO activity was recorded. Subsequently the enzyme activity declined but remained significantly at higher level than the control. The higher PO activity was recorded in resistant cultivar (Fig.1).

The infection effect on ascorbate peroxidase activity of both rice $c v s$ viz., Pusa 1121 (susceptible) and tetep (resistant) was depicted in Fig. 2. The activity of ascorbate peroxidase increased from 1 day after inoculation and the maximum activity was recorded 5 days after inoculation in both the cultivars. Subsequently, the enzyme activity started to decline. It was observed that ascorbate peroxidase (AP) activity in the cultivar Tetep significantly increased from day 1 to days 7 compared to cultivar Pusa 1121 .

Catalase activity significantly increased in both the cultivars 3 days after inoculation with $R$. solani and the highest enzyme activity was recorded 5 days after inoculation subsequently, the enzyme activity decline but remained significantly at higher level than the control. Catalase activity increased rapidly and reached at its peak value on $5^{\text {th }}$ day of infection in both the cvs., however higher catalase activity was recorded in resistant cultivar on infection with $R$. solani (Fig.3). 


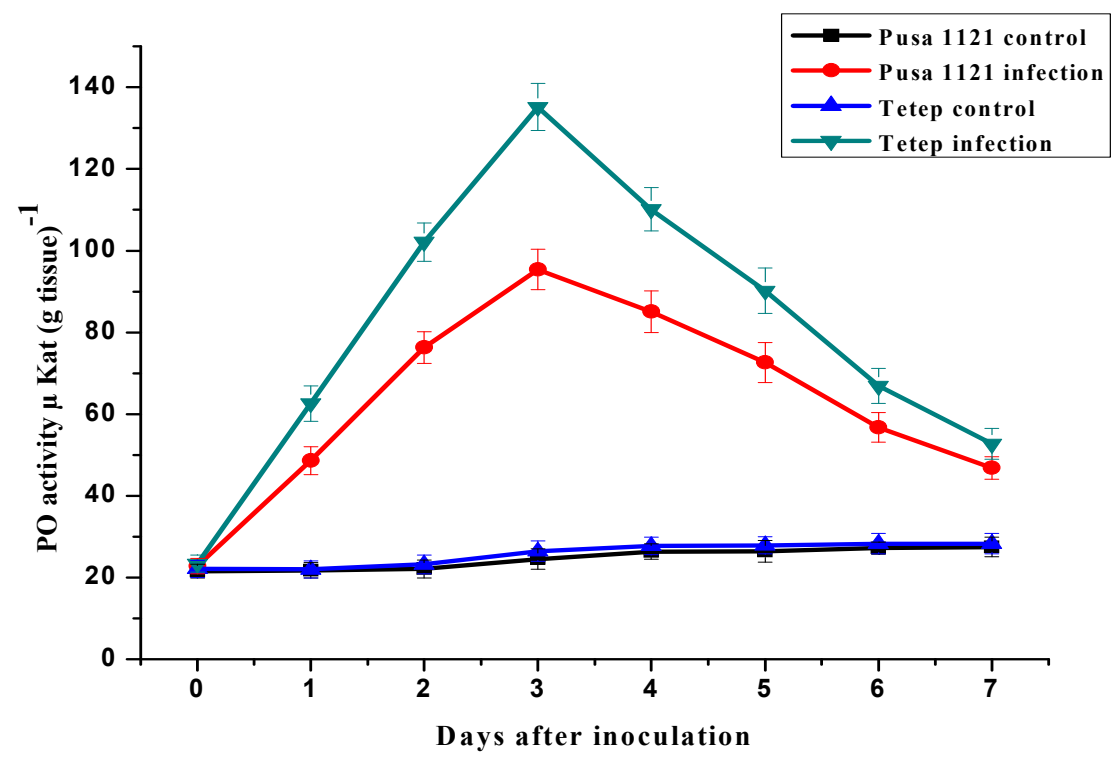

Fig.1: Change in peroxidase (PO) activity in susceptible and resistant cultivars of rice in response to infection with $R$. solani.

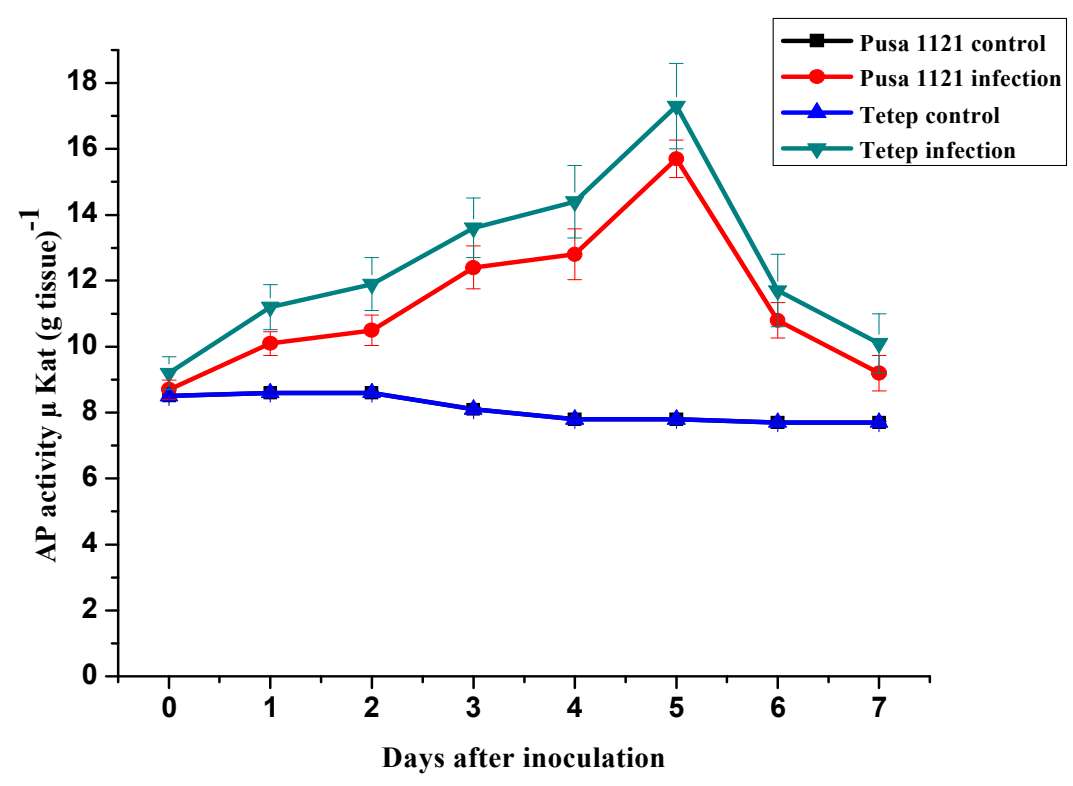

Fig. 2: Change in ascorbate peroxidase (AP) activity in susceptible and resistant cultivars of rice in response to inoculation with $R$. solani. 


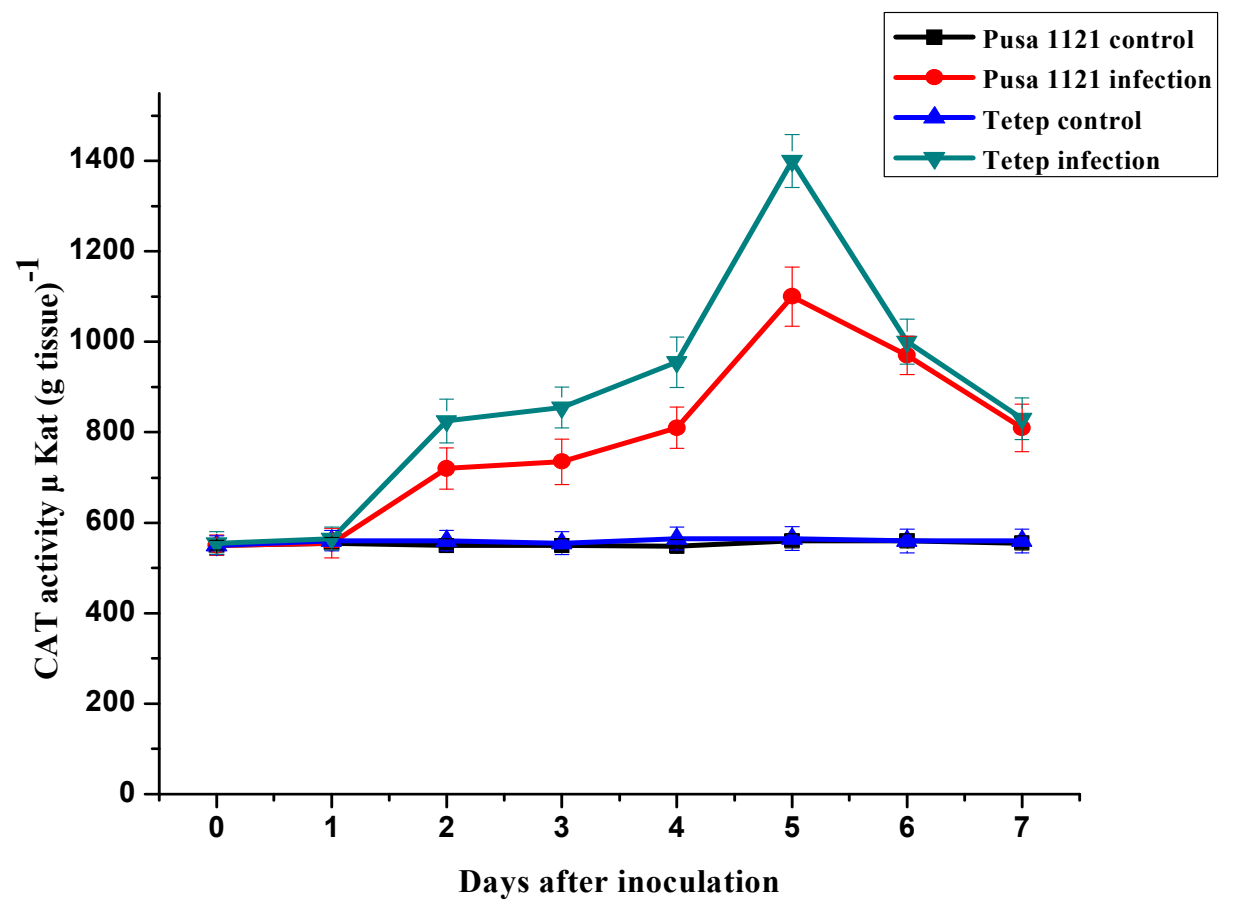

Fig.3: Change in catalase (CAT) activity in in susceptible and resistant cultivars of rice in response to inoculation with $R$. solani.

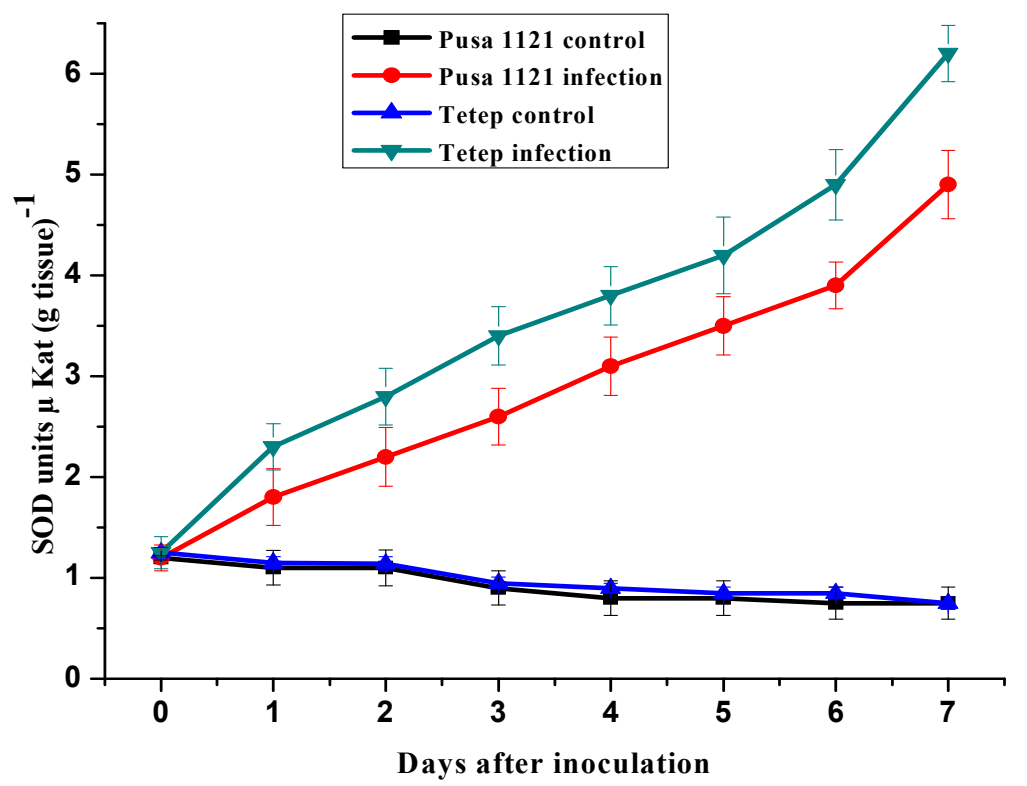

Fig. 4: Change in superoxide dismutase (SOD) activity in susceptible and resistant cultivars of rice in response to inoculation with $R$. solani. 
Superoxide dismutase (SOD) activity was markedly induced after $R$. solani inoculation in both the rice cultivars (Figure 4). Like ascorbate peroxidase, peroxidase and catalase, a clear cut differential induction of superoxide dismutase activity was noticed between a sheath blight susceptible and resistant genotype. This suggested that superoxide dismutase also plays an important role in providing sheath blight resistant development. Significantly increase in SOD activity was observed 2 days after $R$. solani inoculation and the enzyme activity increased gradually up to the end of the experimental period. After 7 days of inoculation it reached $306 \%$ of the uninfected control. The activity was higher in resistant cultivar as compared to susceptible one. A 6-8 folds in increase in enzyme activity was observed on $7^{\text {th }}$ day of infection compared to its initial value on first day of infection.

It has been well documented that during periods of pathogenic stress, products of activated defence genes are synthesised $d e$ novo in several host-pathogen interactions. The rapid elicitation of plant's defence responses mandate that successful pathogenic fungi must have evolved strategies to suppress and/or avoid the responses of potential hosts (Jackson and Taylor, 1996). The necrotropic pathogens normally launch the plant into celldeath programme, thereby short circuiting a strong defence response and providing a ready source of pathogen nourishment (Swords et al., 1999). Several ROS are produced during infection by the pathogens. These active oxygen species have been shown to be associated with the hypersensitive response in plants (Grant et al., 2000). Paranidharan et al., (2003) and Zhang et al., (2006) reported that POD, SOD and CAT are involved in the rice defence response to $R$. solani infection in rice.

In the present study, change in the activities of peroxidase, ascorbate peroxidase, superoxidase dismutase and catalase in susceptible ( $c v$. Pusa 1121) and resistant ( $c v$. Tetep) cultivars of rice in response to infection by Rhizoctonia solani were studied. The results revealed that the activities of antioxidative enzymes viz., peroxidase, catalase, superoxide dismutase and ascorbate peroxidase increased in rice leaf sheaths due to inoculation with $R$. solani. These enzymes activities significantly increased 1-2 days after inoculation and the maximum enzyme activities were detected 5-7 days after inoculation. The higher activity of these antioxidant enzymes are recorded in resistant $c v$. Tetep as compare to susceptible $c v$. Pusa 1121.

Peroxidases are involved in a broad range of physiological processes throughout a plant's life cycle. These enzymes can generate ROS, polymerise cell wall compounds and regulate $\mathrm{H}_{2} \mathrm{O}_{2}$ levels (Passardi et al., 2005). Earlier studies suggest that peroxidases are important PR proteins (Van Loon et al., 1994) and the plant expresses peroxidases activity during host-pathogen interaction (Young et al., 1995; Saikia et al., 2004). The increase in peroxidases activity was correlated with infection in plants (Sridhar and Ou, 1974; Flott et al., 1989). In our study, the peroxidases activity reached at its peak at 3 days after inoculation and maximum reduction of its activity was observed 7 days after inoculation.

Significantly increase in SOD activity was observed 2 days after $R$. solani inoculation and the enzyme activity increased gradually up to the end of the experimental period. After 7 days of inoculation it reached $306 \%$ of the uninfected control. The activity was higher in resistant cultivar as compared to susceptible one. A 6-8 fold in increase in enzyme activity was observed on $7^{\text {th }}$ day of infection compared to its initial value on first day of infection. The enhanced activities of SOD may have helped in the scavenging of the reactive oxygen derivatives which in turn may have led to susceptibility of rice to $R$. solani infection. Increases in the activities of CAT and SOD in plants have been correlated with increased susceptibility to pathogens (Gonner and Schlosser, 1993; Durner and Klessig, 1995). 
Buonaurio et al., (1987) reported that the levels of SOD in bean leaves enhanced during the establishment of the symptoms in the susceptible cultivars following infection with Uromyces phaseoli. Similarly, Fodor et al., (1997) observed increase in SOD activity in tobacco leaves inoculated with tobacco mosaic virus (TMV) after the appearance of necrotic symptoms. E1-Zahaby et al., (1995) observed a substantial increase in ascorbate peroxidase level in the susceptible barley plants inoculated with Erysiphe graminis f. sp. hordei. Riedle-Bauer (2000) observed induction of superoxide dismutases, catalases, peroxidases and ascorbate peroxidases in cucumber leaves infected with cucumber mosaic virus and zucchini yellow mosaic virus.

From the evidences presented above, it could be concluded that the enhanced activities of antioxidative enzymes in $R$. solaniinoculated rice leaf sheaths might have helped in the removal of active oxygen derivatives which might have led to increased susceptibility of rice plants to $R$. solani infection.

\section{Acknowledgement}

The authors are highly grateful to the Department of Recombination Techniques, College of Biotechnology, SVP University of Agriculture and Technology, Meerut for providing laboratory facilities to carry out this investigation. The authors are also thankful to HOD, Department of Genetics and Plant Breeding, SVP University of Ag. \& Tech., Meerut for providing rice cultivars. The corresponding author is grateful to the UGC for awarding Rajiv Gandhi National Fellowship during the period of this research.

\section{References}

1. Aguirre, J., Rios-Momberg, M., Hewitt, D. and Hansberg, W. (2005). Reactive oxygen species and development in microbial eukaryotes.
Trends in Microbiology, 13(3):111180.

2. Apel, K. and Hirt, H. (2004). Reactive oxygen species: metabolism, oxidative stress, and signal transduction. Annual Review of Plant Biology, 55:373-399.

3. Asada, K. (1984). Chloroplasts: formation of active oxygen and its scavenging. Methods in Enzymology, 105: 422-429. doi: 10.1016/S00766879(84)05059-X.

4. Belid ElMoshaty, F.I.B., Pike, S.M., Novacky, A.J. and Seghal, O.P. (1993). Lipid peroxidation and superoxide production in cowpea (Vigna unguiculata) leaves infected with tobacco ring spot virus or southern bean mosaic virus. Physiological and Molecular Plant Pathology, 43: 109-119.

doi:10.1006/PMPP.1993.1044.

5. Buonaurio, R., Dellatorre, G. and Montalbini, P. (1987). Soluble superoxide dismutase (SOD) in susceptible and resistant host-parasite complexes of Phaseolus vulgaris and Uromyces phaseoli. Physiological and Molecular Plant Pathology, 31:173-184.

6. Chance, B. and Maehly, A.C. (1955). Assay of Catalase and Peroxidases. Methods in Enzymology, 11: 764-775. http://dx.doi.org/10.1016/S00766879(55)02300-8.

7. Dangl, J.L. and Jones, J.D.G. (2001). Plant pathogens and integrated defence responses to infection. Nature, 411:826-833.

8. Delledonne, M., Zeier, J., Marocco, A. and Lamb, C. (2001). Signal interactions between nitric oxide and reactive oxygen intermediates in the plant hypersensitive disease resistance response. Proc Natl Acad Sci USA, 98(23):13454-13459. 
9. Dixon, R. A. and Harrison, M. J. (1990). Activation, structure and organisation of genes involved in microbial defense in plants. Advances in Genetics, 28: 165-234.

10. Durner, J. and Klessig, D.F. (1995). Inhibition of and 2, 6dichloroisonicotinic acid, two inducers of plant defense responses. Proc Natl Acad Sci USA, 92:11312-11316.

11. EI-Zahaby, H. M., Gullner, G. and Kiraly, Z. (1995). Effects of powdery mildew infection of barley on the ascorbate-glutathione cycle and other antioxidants in different host-pathogen interactions. Phytopathology, 85: 1225-1230.

12. Flott, B.E., Moerschbacher, B.M. and Reisener, H. (1989). Peroxidase isoenzyme patterns of resistant and susceptible wheat leaves following stem rust infection. New Phytologist, 111:413-421.

13. Fodor, J., Gullner, G., Adam, A.L., Barna, B., Komives, T. and Kiraly, Z. (1997). Local and systemic responses of antioxidants to tobacco mosaic virus infection and to salicylic acid in tobacco. Role in systemic acquired resistance. Plant Physiology, 114(4): 1443-1451.

14. Giannospolitis, C.N. and Ries, S.K. (1977). Superoxide dismutase. Plant Physiology, 59:309-314.

15. Gonner, V.M. and Schlosser, E. (1993). Oxidative sb-ess in interactions between Avena sativus L. and Drechleua spp. Physiological and Molecular Plant Pathology, 42:221-234.

16. Grant, J.J., Yun, B.W. and Loake, G.J. (2000). Oxidative burst and cognate redox signalling reported by luciferase imaging: identification of a signal network that functions independently of ethylene, SA and Me-JA but is dependent on MAPKK activity. Plant Journal, 24(5):569-582.

17. Jackson, A.O. and Taylor, C.B. (1996). Plant-microbe interactions: life and death at the interface. Plant Cell, 8:1651-1668.

18. Lamb, C. and Dixon, R. A. (1997). The oxidative burst in plant disease resistance. Annual Review of Plant Physiology and Plant Molecular Biology, 48: 251-275.

19. Panda, S.K. (2007). Chromiummediated oxidative stress and ultrastructural changes in root cells of developing rice seedlings. Journal of Plant Physiology, 164(11):14191428.

20. Paranidharan, V., Palaniswami, A., Vidhyasekaran, P. and Velazhahan, R. (2003). Induction of enzymatic scavengers of active oxygen species in rice in response to infection by Rhizoctonia solani. Acta Physiologiae Plantarum, 25(1):91-96.

21. Passardi, F., Cosio, C., Penel, C. and Dunand, C. (2005). Peroxidases have more functions than a Swiss army knife. Plant Cell Reports, 24(5):255265.

22. Riedle-Bauer, M. (2000). Role of reactive oxygen species and antioxidant enzymes in systemic virus infections of plants. Journal of Phytopathology, 148: 297-302.

23. Saikia, N.J., Usami, A., Kato, S. and Kojima, T. (2004). Hydration behaviour of eco-cement in presence of metakaolin. Resource Progress, 51:35-41.

24. Sridhar, R. and Ou, S.H. (1974). Phenolic compounds detected in rice blast disease. Biologia Plantarum, 16:67-70.

25. Srivastava, S.K. (1987). Peroxidase and polyphenol oxidase in Brassica juncea plants infected with Macrophomina phaseolina (Tassi) 
Goid and their implications in disease resistance. Phytopathology, 77: 249254.

26. Swords, K., Liang, M.M.J. and Shah, D.M. (1999). Novel approaches to engineering disease resistance in crops. Genetic Engineering, 19:1-13.

27. Van Loon, L.C., Pierpoint, W.S., Boller, T. and Conejero, V. (1994). Recommendations for naming plant pathogenesis-related proteins. Plant Molecular Biology Reporter, 12:245264.

28. Young, S.A., Guo, A., Guikema, J.A., White, F. and Leach, I.E. (1995). Rice cataionic Peroxidase accumulation in xylem vessels during incompatible interactions with Xanthomonas oryzae pv. oryzae. Plant Physiology, 107:1333-1341.

29. Zhang, M., Haapasalo, A., Kim, D.Y., Laura, A., Ingano, M.K., Pettingell, W.H. and Kovacs, D.M. (2006). Presenilin $/ \gamma$-secretase activity regulates protein clearance from the endocytic recycling compartment. FASEB Journal, 20: 1176-1178. 